\title{
Gender Differences In Computer Usage
}

\author{
M.Sadiq Ali Khan \\ Department of Computer Science \\ University of Karachi
}

\begin{abstract}
Today in every walk of life both genders play their own roles in all fields which creates equilibrium in respected fields. This balance is seemed to be falling apart in the field of computers due to the comparatively less representation of female in this field. There are many reasons of this gender imbalance which seem to define computer technology as a male dominating field. Computers have intruded our lives in a big way. This technology has much evolved in the past two decades, and now it has become part of our lives. In today's world the growth of the internet has changed the social dynamics. This includes their personal interaction with all others and the ways they form communities. In this article facts are highlighted that how society and personal relationship are changing in the computer's age, and I highlighted some measures that can be helpful to reduce the gender bias at any work place.

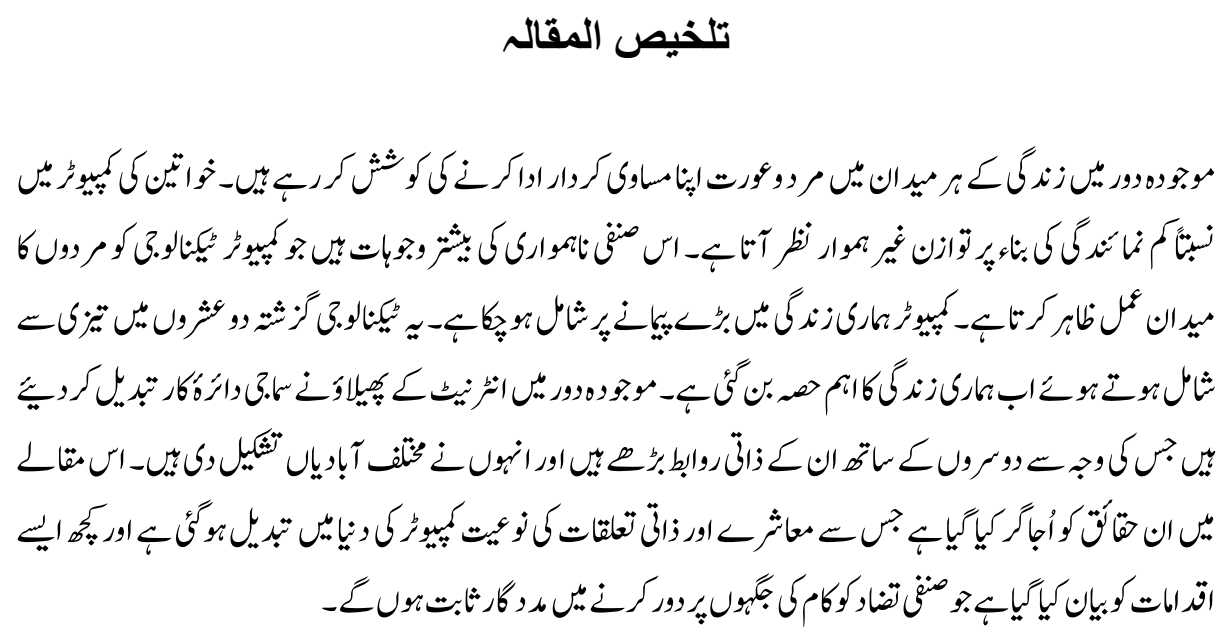

\section{Introduction}

Computer has integrated in every discipline of our lives may it be management, art, education, business etc. Computers are not just Personal Computers, different kinds of computer systems called expert system are used according to the needs of the environment and user. Computers have eased our lives, but this ease is available for lesser part of the population. The growth of this technology has been remarkable in urban areas still in rural areas it is scarce. Factors of this difference might be low literacy rate, culture, govt. policies etc. Other than this there are other reasons which are affecting 
computer usage in urban areas too. The major factors are anxiety, limited resources, gender, attitude, computer literacy etc.

The fact that computer technology is evolving rapidly, in a very short span of time new technology is introduced and the older become outdated. This is the greatest difficulty to cope with the cost of the new technology and to get equipped with the new needs. To live in this information age one has to be highly equipped and must have the strength to transform easily, which makes users anxious. Anxiety may cause an inefficient and contradictory performance. Computer anxiety is one of the biggest factors affecting computer usage. In a country like ours less opportunities of learning computers are available due to the limited resources in our country, only a very few number of candidates are selected. This leads to a lack of interest in joining this field.

Talking about attitude towards computer comprises of feelings, social pressures, perceptions etc. Attitude is another factor which affects the computer usage most. Computer Literacy points to the knowledge of computer as a machine or system. It takes time and hard work to gain this knowledge. It can be the know how of applications and programs of computer to a much higher level of programming and discovery.

\section{IT: As a Career for Women's}

Female hesitate to join this field from a very ground level due to misconceptions and misinterpretations. Male get a better chance and are more passionate about this field as a career or learning. Also the core factor of this imbalance is social pressure as women here are protected and taken care of which leads to confined boundaries in every aspect. Men in contrast are independent and have much easier access to computers. Pakistan is a country where people follow there custom and traditions very respectfully. Till date son is considered to be the name carrier and is given more privileges as compare to a daughter. Son's career and education is considered important as apposed to a daughter, it is primarily due to the thinking 'she has to get married and become a home maker; career is of no importance to her'. Information Technology (IT) is a field which is considered to be very tough for a daughter to handle, where as for a son it is said to be a good career.

The percentage of female students in computer sciences is rising day by day but on a very slow pace. Male students are still predominant. One of the biggest reason is that computer education is costly than other disciplines. This makes it unreachable for females. Career in computer science is difficult to make and sustain, it has very different working styles. It is a full time job that is a 9 to 6 work. It needs a lot of passion, patience and time. The people involved in this profession are called geeks, nerds and socially isolated people. These conditions are considered difficult for women to handle as she has also to take care of her home and family. 
According to some researches, females like less technical and more social oriented professions where interaction is with people not machines. They find it dry and non attractive. Females seem to have negative thinking about computer sciences due to the above given reasons. To talk about the computer education, it starts from more or less $1 \mathrm{st}$ grade. At starting gender representation is more or less same but when moving up male dominance increases (Wendy Faulkner, 2000).

\section{Computer Education for Women's}

Computer Education has now become a vital part in early education, in most of the countries computer classes starts from grade 1 to educate children the modern language (computers). As the child climbs up to Matriculation, minds of children are made either to take science, arts or commerce. If science; then there are two choices biology or computers. Most males prefer computers but, when we talk about girls they usually prefer biology. That is the point where the difference starts building up. On Intermediate level there is an admission system used called CAP (Central Admission Policy) which is used to give admission in colleges on merit as seats are limited and applicants are much more. Talking about computer at intermediate, very few colleges offer computer at this stage and seats are much limited as compared to other disciplines. Fewer seats in female colleges than males. Now talking about the graduate level. Aptitude tests now become the criteria of selection. Applicants are much more than the capacity. For example for 60 seats 500 people would apply for admission in computer science. Curriculum of computers also becomes quite difficult as compared to other subjects are to be studied. This becomes difficult for females to concentrate.

\section{Background}

The focal point of concern is the absence of women's in computer science programs and jobs in the Information Technology sector. Masculinisation of computing culture, power relations and the less valuing of womanly skills are the key factors that discourage women's involvement in the IT sector (Andrea H. Tapia: Lynette Kyasny, 2004). After interviewing with IT professionals women's, reports resulted that womanly skills, while viewed as useful in the IT industry may actually work against women's advancement to upper management. Some authors suggested that the cycle of women's omission from computer science can be broken at the interface design stage, through consideration of 'the female perspective' at the design stage. After reviewing literature related to the cycle of imbalance, the authors focus on gender differences in human computer interaction (Moore, J.E. and L.A. Burke, 2000).

According to results from past researches the state of gender equilibrium is soon to be achieved but, in the perspectives of self efficiency and access. The gender gap is also 
reported to be less in the field of education. As far as usage is concerned male user spend more time then female on daily basis, also males are much more efficient in software usage. Not only computing itself had become masculine; it also had become a part of our social cognitive scheme with which we can make sense to the world (Balka E, Smith R). Frames of references for this new technology have influenced other processes on an organizational and occupational level that constituted the computer's gender-biased entrenchment in society (Hapnes, T. And Rasmussen, B, 1991). It is worth noting that gender differences in computer attitudes increase with age (American Association of University, 2000, Barker, L. J., \& Aspray, W., 2006). One might speculate that there is a similar relationship between computer confidence and ability for elementary boys and girls, although more research is needed to support this theory (Kay, R. H., 2006, Butler, D., 2000).

\section{Role of Computers: Gender Influenced}

A critical question arises as to whether computer behavior is influenced by gender. If computers play an increasingly prominent role in our society, one could argue that significant power and success rest with those who know how to use this technology effectively. It seems vital that both genders have equal opportunities to learn computers, but the difference prevails due the positive attitude and better abilities of males in computer usage (Kay, R. H., 1992). More recent literature reviews show that male dominance is still prevalent with respect to computer attitudes, ability and use. A majority of this research, though, looks at teens and adults (American Association of University, 2000, American Association of University, 2002, Barker, L. J., \& Aspray, W.,2006, Kay, R. H., 2006, Butler, D., 2000). Computers are being used in a variety of disciplines but still it can be used in every discipline of learning. Focusing on a curriculum that emphasizes learning specific computer skills out of context may discourage girls from using computers. Researches made it evident that using computer in the elementary school level as a problem solving system is a wise step. Now talking about computer as an entertainment package or a reward for some good work should be discouraged as it stimulates the aggressiveness in males (teens) and time mismanagement for females (teens). The biggest reason of females backing off is because of the more self-confident and self-efficient males. To use computer application on an elementary

level the instructors must be well literate so that they can design a well structured and effective lessons.

\section{Educational System}

In addition, gender perceptions will never change unless female teachers demonstrate that they are capable users of technology. In educational system the gender difference is reported much higher then other disciplines. The biasness in computers is due to the usage behaviours. Parents and teachers should be aware to cultural biases and make every 
effort to expose both sexes to the benefits of computer technology. New ideas should be devised in order to promote greater gender equity in computer use and help close the technological gap between boys and girls (Challoo, L. \& Alaniz, L., 2006). Educators must find a way of making curriculum more interesting as well as educating. Both gender students use computer applications that can be associated to the educational setting such as word processing, accessing information, and completing assignments and projects. But students also use computers for communication, self-expression, and personal interest (Asuquo, E. N; Nasanya, S. A.). The way female relates to the technology and there work is forgotten in education. As soon as the education specialist understand the difference of gender and recognize the behaviour of the learners this gap might get thinner. Today women should be given more importance then men in pulling computer as there prime learning (Venakesh, V. And M.G., 2000).

\section{Gender Bias in the Workplace}

Gender bias is basically the differentiation between the employees on the bases of the characteristics of a man and women. It is considered as a fact that males are more competent, assertive and reliable in the technical fields then the women. And even small judgments based on gender bias certainly do have powerful impact on women's careers. It is well known that men benefit more from their accomplishments than women, and even small imbalances accumulate over time and cause women to advance at a slower rate then men. Very few females really opt technical fields knowing the facts and challenges they might have to face while performing their jobs would not be easy to go with. There are very few females who pick such technical lines as their career and they have to have certain things in mind like there are no time limits and even one has to troubleshoot things irrespective of the technicality and place. And hence the ratio of females is very less as compared to the males.

Many skilled women on the way up still feel the need to prove themselves. These are the women you see who are completely ambitious. The career comes before anything else. All too often the cost is one's individual life. They are not able to give the time and attention their family requires from them and hence they have to set priorities over their own wishes.

\section{Patterns of Gender}

Von Hellens(2002) identify the following most common patterns of gender bias encountered in the workplace in the IT job market.

a) Motherly Wall: The strongest and most explicit bias in today's workplace is against mothers. Generally, motherly wall bias is triggered when motherhood becomes 'salient' or obvious to managers and colleagues. 
b) She isn't Experienced: Women need to provide more facts of job-related skills than their male counterparts before they are viewed as competent.

c) What a Witch! Conduct that is acceptable in men often is considered unacceptable in female. A female in a traditionally male job may be called a 'witch,' 'hard to work with' or 'too ambitious' - for the same conduct that helps a man establish himself as 'assertive' and 'having leadership potential.' In some workplaces, women are seen either as friendly or dependent women who are nice but unskilled or as nontraditional women who are capable, but are not accepted for violating unspoken norms that women should be comprehensive and cultivated (Von Hellens, L.A., S.H. Nielsen, and E.M. Trauth, 2001).

\section{Observations \& Discussions}

When talking about home makers or simply house wives the percentage is very low, as they get very fewer times for themselves. The homemakers are considered to be just to take care of their families and their home as compare to their self. For this research interviews from different age group was conducted. These include house wives categorise in to three age group as shown in Table 1, one age group is of young females, two other groups of elder women.

The results we found that computer usage in these women is meagre. They have very less time for computer usage. In Pakistani society usually when a girl gets married, her lifestyle changes, she leaves her education and learns how to do house chores which makes her confined to her home and children therefore the percentage of usage of computer is very low.

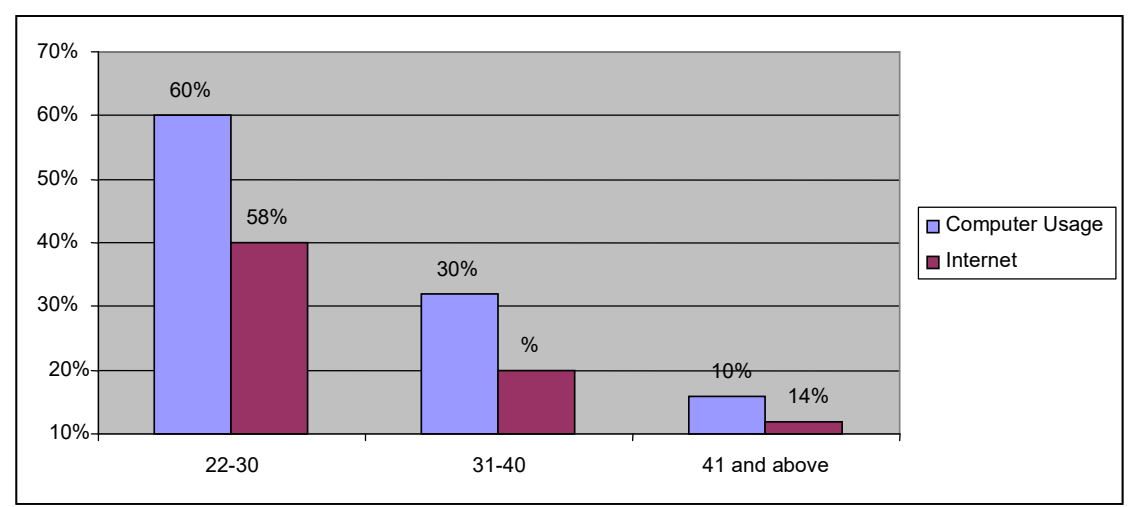

Fig 1: Representation of usage of computer in different age group as house wife

Talking about the first age group, in young women the percentage of computer usage is much higher then that of other group as they are considered to be much modern and 
educated then other age groups. There education level is higher than the other group. They use computers for entertainment and for keeping in touch with there friends and family. Social Networking and Email are the most used applications on the net. Also cooking portals are very much used.

The second age group defines the middle age women whom are reluctant in using computers and know very little about them. They use computer just for their knowledge or just for entertainment purpose.

The last age group has the least number of users less then $5 \%$. Most of them just know about how to open a computer. Only less then a percent knows about internet and its services. This age group considers computer as a new generation technology and considers themselves as outdated. They don't want to use this technology unless or until there loved ones are far in another country and internet becomes the most convenient option for contact to those people.

Table 1

Computer usage statistics for house wives

\begin{tabular}{|l|c|c|}
\hline \multicolumn{1}{|c|}{ Age Group/Usage } & Computer Usage & Internet \\
\hline $\mathbf{2 2 - 3 0}$ & $60 \%$ & $58 \%$ \\
\hline $\mathbf{3 1 - 4 0}$ & $30 \%$ & $28 \%$ \\
\hline $\mathbf{4 1}$ and above & $10 \%$ & $14 \%$ \\
\hline Total & $100 \%$ & $100 \%$ \\
\hline
\end{tabular}

When talking about professionals computer usage as shown in Table 2 is evident. They use computers both in their homes as well as work. They are the skilled users of computers who know there applications well and who work on computer for more then 10 hours a day.

Table 2

Table 2: Computer usage for professionals as per area

\begin{tabular}{|l|c|c|}
\hline Area/Usage & Computer Usage & Internet \\
\hline Work Place & $65 \%$ & $62 \%$ \\
\hline Home & $35 \%$ & $38 \%$ \\
\hline Total & $100 \%$ & $100 \%$ \\
\hline
\end{tabular}




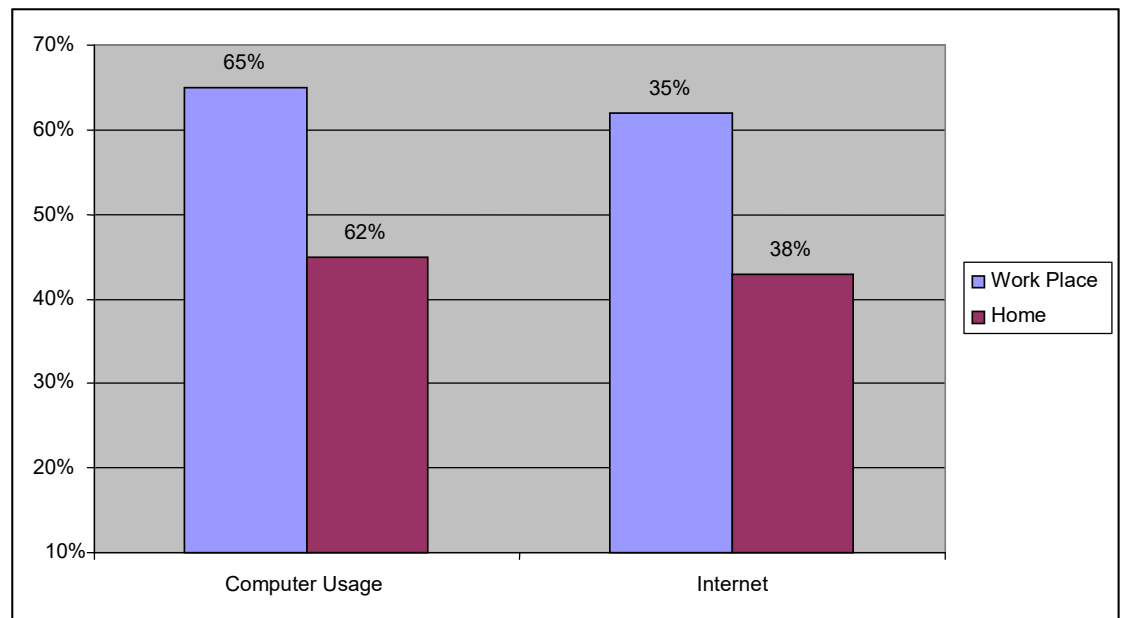

Fig 2: Percentage of computer usage in Professionals women's

Table 3

Computer usage by professionals as their requirement

\begin{tabular}{|l|c|c|}
\hline Type of work/Hours a day & Computer Usage & Internet \\
\hline Entertainment & $3 \mathrm{hrs}$ & $2 \mathrm{hrs}$ \\
\hline Work & $8 \mathrm{hrs}$ & $5 \mathrm{hrs}$ \\
\hline Knowledge & $2 \mathrm{hrs}$ & $1.5 \mathrm{hrs}$ \\
\hline
\end{tabular}

Professional women use computer both at home and on work, the usage of computer for them is a responsibility as in this field timings are not absolute. One has to work day or night for completion of their work and to meet the deadline. Also in organizations, women are allowed to take work home and complete it. As far as male dominance is concerned women mostly don't agree to it, they think women in IT industry are a little less but still they play an important role in this industry. Talking about the problems they faced in the industry are mostly time managing problems. Some time women also feel themselves aliens as there are less in number in the organizations.

When talking about students, a survey was conducted with female student of BS studying computer science as their major subject. Approximately each one of them used computer at home as it is their study need, most of their research and projects are prepared on the computers. They think that computer is a necessity they need for completing their degree and they can't live without it. Most of them wanted to pursue IT as a carrier and had decided to pursue it as a carrier. The students were much more literate in a general perspective. They know about there software and hardware well and also wanted to make a difference to the computer world. Most of them were interested in studying further in the field of IT. There computing knowledge was better then the other groups due to the fact that most of them were using computers for more then 10 years. 


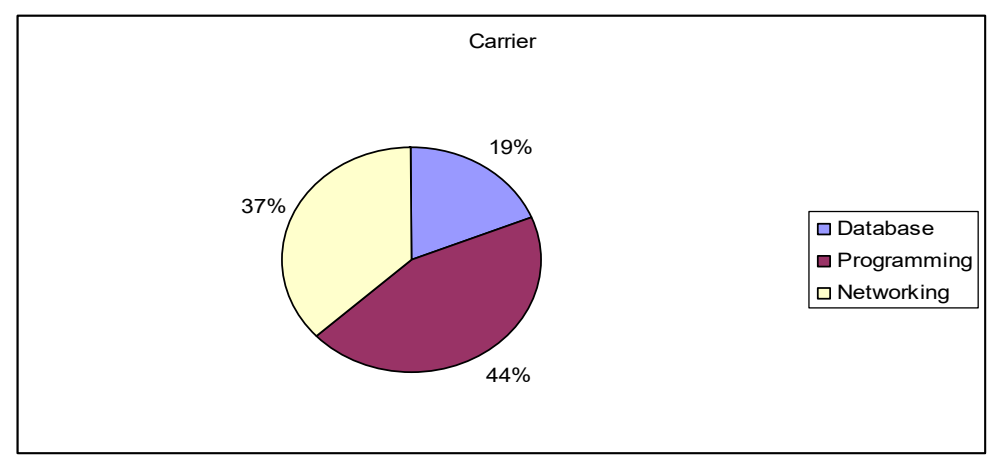

Fig 3: Percentage of women's selecting computer fields as their carrier

When talking about Internet and Web, approximately everyone was well aware about the new advancements and was educated about the web pages 'in' these days. Most of them also used internet for virtual books and reading researches and also blog their thoughts regularly. Some of them even added there work on the internet. The entertainment phase also existed in which students were much interested in social networking and virtual games. Also used internet for contacting their friends through email.

It was evident in the questionnaire that students most likely first check their mail and educational groups whenever they use the internet. A very big bunch of students wanted to pick database as their major in further studies as referred in Table 4 and as a carrier. Programming was very rare which very few students wanted to do.

Table 4

Interest areas for female students studying Computer Science

\begin{tabular}{|l|c|c|c|}
\hline Area/Discipline & Database & Programming & Networking \\
\hline Further Study & $80 \%$ & $5 \%$ & $15 \%$ \\
\hline Career & $19 \%$ & $44 \%$ & $37 \%$ \\
\hline
\end{tabular}

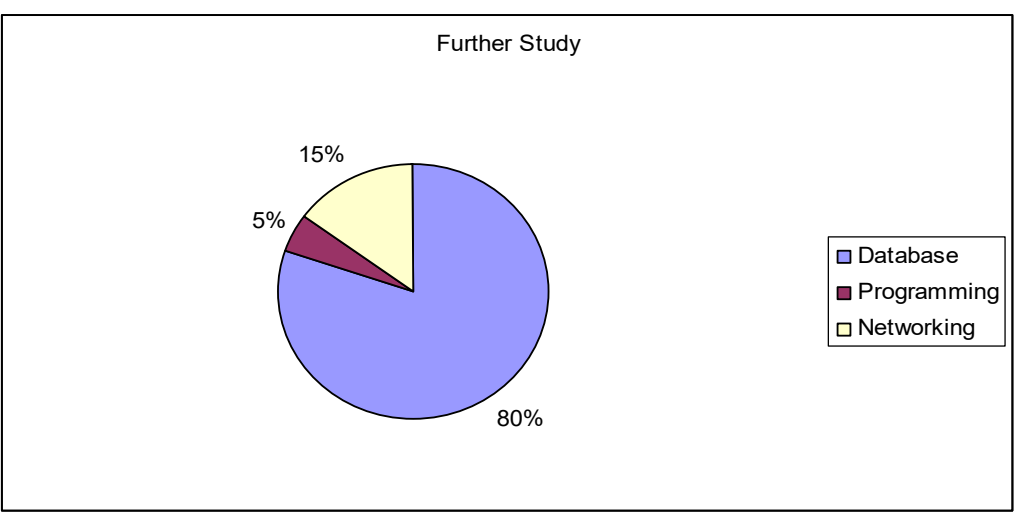

Fig 4: Percentage of women's for further study in computer fields 


\section{Conclusions \& Results}

As the need of computers in education is also increased, attention moved to what increased use of computers for the education will mean for women. Some female students might use their laptops in preparing the classroom assignments, there is a need to create an excellent on-line learning environment for women and as a teacher we can also help in modernizing a culture by enforcing students to use computers in their day to day life. At the time of the rise of the female era in the mid sixties, computing was deeply masculinised in all three aspects of gender studies, through gender symbolism, gender structure, and gender identities. Talking about today employment in the IT industry has been similar for both genders. Gender differences have changed with the passage of time and as the computer technology prevailed. Computer systems have become essential for working environment as it is much easier then manual system. Today's women can be classified both as a developer and structure modeller.

Following measures can be helpful to remove the gender bias at any work place. Human resources should evaluate both the verbal communication and application of personnel policies that may allow biases to steal into employment decisions. Relevant policies includes attendance, leave, availability and form of alternative work schedules, compensation, the lack of written objective hiring and promotion criteria. Human resources should also review interviewing, evaluation and disciplinary procedures; hiring, promotion, termination and compensation rates between male and female employees.

Having a place of work that is free from gender bias is becoming a business crucial as companies struggle for employees and customers. Companies that work to eradicate bias will gather plenty rewards - as well as have the satisfaction of knowing they are doing the right thing. It is wrong to judge ones capabilities on the bases of gender. At times it is observed that females are more organized and enthusiastic with more innovative ideas. Indeed agreed to a fact that males are more reliable and suitable in the technical fields where timings is not an issue but ones efficiency should not be judged on the bases of gender as it would not be fair to judge ones potentials on gender characteristics.

\section{References}

American Association of University Women (2000) Tech-savvy: Educating girls in the new computer age. Retrieved December 1, 2006, from http://www.aauw.org/ member center/ publications/TechSavvy/TechSavvy.pdf.

American Association of University Women (2002) Gender gaps: Where schools still fail our children. Retrieved December 1, 2006 from http://www.aauw.org/ research/ GGES.pdf. 
Andrea H. Tapia; Lynette Kyasny (2004) Recruitment is Never Enough: Retention of Women and Minorities In the IT Workplace. SIGMIS'04, April 22-24, 2004, Tucson, Arizona, USA.

Asuquo, E. N; Nasanya, S. A. (2006) “Gender Differences and Students' Achievement in Computer Technology Instruction" In West Africa journal of Educational Research Vol. 9. Nos 1 \& 2, September.

Barker, L. J., \& Aspray, W. (2006) The state of research on girls and IT In J. M. Cohoon \& W. Aspray (Eds.), Women and information technology (pp. 3-54). Cambridge, MA: MIT Press.

Balka, Ellen and Smith, Richard (2000) Women, work and computerization: Charting a course to the future, Klumer Academic Publications.

Butler, D. (2000) Gender, girls, and computer technology: What's the status now? Clearing House, 73(4), 225-229.

Challoo, L. \& Alaniz, L. (2006) Gender Differences In Computer Use Of 7th Graders In A Secondary School In C. Crawford et al. (Eds.), Proceedings of Society for Information Technology \& Teacher Education International Conference 2006 (pp. 3866-3871). Chesapeake, VA: AACE.

Hapnes, T. and Rasmussen, B. (1991) The production of male power in computer science In Eriksson, I.V., B.A. Kichenham and K.G. Tijdens, women work and computerization; understanding and overcoming bias in work and education . p.g 395-406.

Kay, R. H. (1992) An analysis of methods used to examine gender differences in computer-related behaviour In Journal of Educational Computing Research, 8, 323-336.

Kay, R. H. (2006) Addressing gender differences in computer ability, attitudes and use: The laptop effect In Journal of Educational Computing Research, 34, 187-211.

Moore, J.E. and L.A. Burke (2002) How to Turn Around 'Turnover Culture' In IT. Communications of the ACM, 45(2): p. 73-78.

Venakesh, V. and M.G. Morris (2000) Why Don't Men Ever Stop To Ask For Directions: Gender, Social Influence And Their Role In Technology Acceptance And User's Behaviour In MIS Quarterly, 24(1): p. 115-139. 
Von Hellens, L.A., S.H. Nielsen, and E.M. Trauth, (2001) Breaking and Entering the Male Domain Women In the IT Industry In ACM SIGCPR. 2001. San Diego.

Wendy Faulkner. (Oct., 2000) Dualisms, Hierarchies and Gender in Engineering ; Social Studies of Science, Vol. 30, No. 5, pp. 759-792; Sage Publications, Ltd.

M. Sadiq Ali Khan is Assistant Professor in the Department of Computer Science, University of Karachi 